\section{Correspondence on 'Role of joint damage, malalignment and inflammation in articular tenderness in rheumatoid arthritis, psoriatic arthritis and osteoarthritis'}

With great interest we read the article of Gessl et al that studied whether tenderness of non-swollen small hand joints was explained by subclinical inflammation as detected by ultrasound (US). Interestingly, the findings in rheumatoid arthritis (RA) were dependent on the disease stage: tenderness in longstanding RA (mean disease duration 7.2 years) was not associated with subclinical inflammation, while in early RA (disease duration $<2$ years) tenderness of hand joints was associated with subclinical inflammation $(54.5 \%$ of tender joints vs $48.4 \%$ of non-tender joints showed inflammation; OR 2.22). ${ }^{1}$ Since validation of research findings is of utmost importance, we hypothesised that the findings observed in early clinical RA would correspond to similar findings in the symptomatic phase that precedes clinical inflammatory arthritis and RA. ${ }^{2}$ It is important to understand whether joint tenderness in patients with clinically suspect arthralgia (CSA) is related to subclinical inflammation, since joint swelling is per definition absent in this phase.

This prompted us to perform a validation study in CSA patients. We studied the association of joint tenderness in metacarpophalangeal (MCP) joints with subclinical inflammation as determined by MRI. We focused on MCP joints since these joints are included in the EULAR definition of arthralgia suspicious for progression to RA. ${ }^{3}$ On the contrary to Gessl et al, who used US examination for determining the presence of subclinical inflammation, we used MRI. According to the EULAR imaging taskforce, both MRI and US have an added value when diagnosing patients in the early disease phases of RA. ${ }^{4}$ US has advantages in terms of costs and availability. MRI in contrast is more sensitive; especially for tenosynovitis, the sensitivity of US compared with MRI is moderate-low. ${ }^{5}$ To prevent false negative findings due to missing subtle subclinical inflammation in the phase of CSA, MRI was implemented in our study.

Between April 2012 and February 2019, 602 patients were consecutively included in the Leiden CSA cohort and assessed for MCP tenderness by physical examination at baseline. Patient-reported joint pain was also assessed by using a mannequin. Unilateral MRI of the MCP (2-5) joints was made and scored for subclinical inflammation (synovitis, tenosynovitis, osteitis) by two experienced readers, blinded for clinical data, as described previously and in the online supplemental file. $^{2}$ Presence of subclinical inflammation was determined after referring to MRI findings of MCP joints of symptomfree controls of the same age. ${ }^{6}$ Data of tenderness and inflammation in ipsilateral MCP joints were studied. Analyses were done in all patients presenting with CSA and in the subgroup that progressed to inflammatory arthritis within 2 years follow-up (in retrospect these patients were truly 'pre-RA' when presenting with arthralgia). A flowchart of the studied population and baseline characteristics are presented online supplemental figure 1 and table 1 .

In all CSA patients, $38 \%$ of patients with tender MCP joints had subclinical inflammation compared with $25 \%$ of patients with non-tender MCP joints (OR 1.84 (95\% CI: 1.29 to 2.63); figure $1 \mathrm{~A}$, online supplemental table $2 \mathrm{~A}$ ). At patient level, MCP tenderness was associated with subclinical synovitis and tenosynovitis (OR 1.76 (95\% CI: 1.10 to 2.81), OR 1.69 (95\% CI: 1.12 to 2.55 ), online supplemental table $2 \mathrm{~A}$ ) but not with osteitis. In the subgroup of patients who progressed to clinical arthritis $(n=87), 61 \%$ of patients with tender MCP joints had subclinical inflammation compared with $46 \%$ of patients with non-tender joints (OR subclinical inflammation 1.79 (95\% CI: 0.74 to 4.30 ), figure $1 \mathrm{~B}$, online supplemental table 2A). Studying the $39 \%$ of patients who presented with MCP tenderness without subclinical inflammation at MRI and who later on developed IA revealed that clinical arthritis had mostly $(85 \%)$ developed in joints that were not scanned, hence being left unanswered whether these patients had subclinical inflammation at presentation with CSA in joints that were not imaged. The remaining patients (15\%) did develop clinical arthritis in MCP joints that were imaged but were normal at first presentation, suggesting that subclinical inflammation developed after CSA onset. Evaluating patient-reported MCP pain (mannequin) instead of MCP joint tenderness at physical examination showed similar associations with subclinical inflammation (online supplemental figure 2, table 2B).

Concluding, associations of joint tenderness with subclinical inflammation in the symptomatic phase preceding clinical arthritis had roughly similar effect sizes as observed in the phase of clinical arthritis. Hereby, we validated and expanded the findings of Gessl et al in early RA.
A

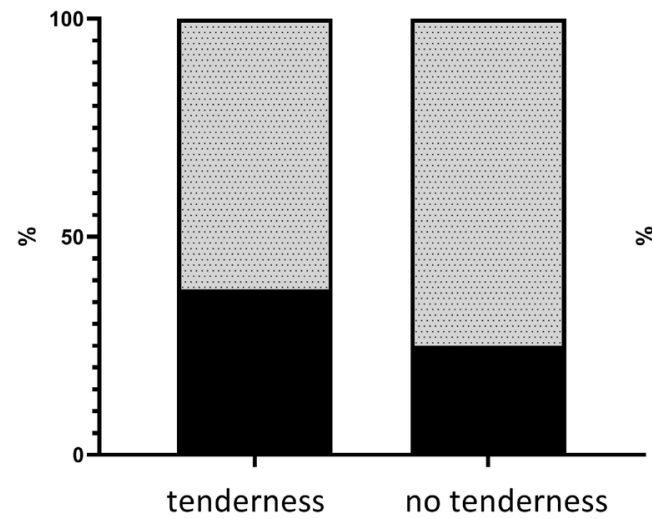

B

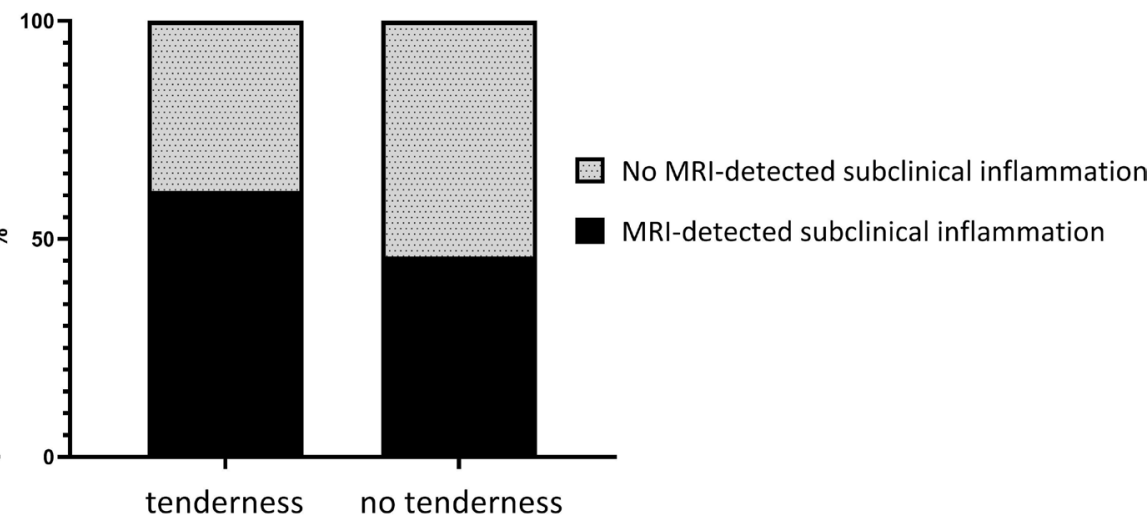

Figure 1 (A) Association of subclinical inflammation with tender MCP joints ( $N=226$ with tenderness vs $N=376$ without tenderness): $0 R 1.84,95 \%$ $\mathrm{Cl} 1.29$ to 2.63. (B) Association of subclinical inflammation with tender MCP joints in patients who developed inflammatory arthritis ( $\mathrm{N}=33$ with tenderness vs $\mathrm{N}=54$ without tenderness): OR $1.79,95 \% \mathrm{Cl} 0.74$ to 4.30 . 
Quirine A Dumoulin $\odot,{ }^{1}$ Xanthe M E Matthijssen $\odot$, ${ }^{1}$ Fenne Wouters $\odot ~, '$ Doortje I Krijbolder, ${ }^{1}$ Ellis Niemantsverdriet $\odot{ }^{1}$ Annette H M van der Helm-van Mil ${ }^{1,2}$

${ }^{1}$ Rheumatology, Leiden University Medical Center, Leiden, The Netherlands ${ }^{2}$ Rheumatology, Erasmus Medical Center, Rotterdam, The Netherlands

Correspondence to Quirine A Dumoulin, Rheumatology, Leiden University Medical Center, 2333 ZA Leiden, Netherlands; q.a.dumoulin@lumc.nl

Contributors QAD, XMEM and AHMvdH-vM contributed to the conception and study design. QAD analysed the data. All authors contributed to the interpretation of the data and read and approved the final version of the document. XMEM, FW, DIK and EN contributed to the acquisition of the data. QAD, EN and AHMvdH-vM wrote the first version of the manuscript. XMEM, FW and DIK contributed to the critical revision of the manuscript.

Funding This work was supported by the European Research Council (ERC) under the European Union's Horizon 2020 research and innovation programme and the Dutch Arthritis Foundation.

Competing interests None declared.

Patient consent for publication Not required.

Ethics approval The Medical Ethics Committee of the Leiden University Medical Center (METC LUMC) has approved this study. Participants gave informed consent to participate before taking part in the studied cohort.

Provenance and peer review Not commissioned; internally peer reviewed.

Data availability statement Data are available upon reasonable request.

Supplemental material This content has been supplied by the author(s). It has not been vetted by BMJ Publishing Group Limited (BMJ) and may not have been peer-reviewed. Any opinions or recommendations discussed are solely those of the author(s) and are not endorsed by BMJ. BMJ disclaims all liability and responsibility arising from any reliance placed on the content. Where the content includes any translated material, BMJ does not warrant the accuracy and reliability of the translations (including but not limited to local regulations, clinical guidelines, terminology, drug names and drug dosages), and is not responsible for any error and/or omissions arising from translation and adaptation or otherwise.

(C) Author(s) (or their employer(s)) 2021. No commercial re-use. See rights and permissions. Published by BMJ.

- Additional supplemental material is published online only. To view, please visit the journal online (http://dx.doi.org/10.1136/annrheumdis-2021-220511).

\section{Check for updates}

To cite Dumoulin QA, Matthijssen XME, Wouters F, et al.

Ann Rheum Dis Epub ahead of print: [please include Day Month Year]. doi:10.1136/ annrheumdis-2021-220511

Received 9 April 2021

Accepted 4 June 2021

\section{SLinked}

- http://dx.doi.org/10.1136/annrheumdis-2021-220922

Ann Rheum Dis 2021;0:1-2. doi:10.1136/annrheumdis-2021-220511

\section{ORCID iDs}

Quirine A Dumoulin http://orcid.org/0000-0003-0318-096X

Xanthe M E Matthiissen http://orcid.org/0000-0001-7332-8072

Fenne Wouters http://orcid.org/0000-0002-4375-4043

Ellis Niemantsverdriet http://orcid.org/0000-0002-5781-3817

Annette H M van der Helm-van Mil http://orcid.org/0000-0001-8572-1437

\section{REFERENCES}

1 Gessl I, Popescu M, Schimpl V, et al. Role of joint damage, malalignment and inflammation in articular tenderness in rheumatoid arthritis, psoriatic arthritis and osteoarthritis. Ann Rheum Dis 2021;128:annrheumdis-2020-218744.

2 van Steenbergen HW, van Nies JAB, Huizinga TWJ, et al. Characterising arthralgia in the preclinical phase of rheumatoid arthritis using MRI. Ann Rheum Dis 2015;74:1225-32.

3 van Steenbergen HW, Aletaha D, Beaart-van de Voorde LJ, et al. EULAR definition of arthralgia suspicious for progression to rheumatoid arthritis. Ann Rheum Dis 2017;76:491-6.

4 Colebatch AN, Edwards CJ, Østergaard M, et al. EULAR recommendations for the use of imaging of the joints in the clinical management of rheumatoid arthritis. Ann Rheum Dis 2013;72:804-14.

5 Wakefield RJ, O'Connor PJ, Conaghan PG, et al. Finger tendon disease in untreated early rheumatoid arthritis: a comparison of ultrasound and magnetic resonance imaging. Arthritis Rheum 2007;57:1158-64.

6 Mangnus L, van Steenbergen HW, Reijnierse M, et al. Magnetic resonance ImagingDetected features of inflammation and erosions in symptom-free persons from the general population. Arthritis Rheumatol 2016;68:2593-602. 